\title{
O PROJETO PROFISSIONAL DO JOVEM NO CONTEXTO DA ESCOLA FAMÍLIA AGRÍCOLA DE SANTA CRUZ DO SUL
}

\author{
Adair Pozzebon ${ }^{1}$ \\ Flávia Charão-Marques ${ }^{2}$
}

\section{RESUMO}

Este artigo descreve e analisa o processo de elaboração e desenvolvimento do Projeto Profissional do Jovem - PPJ na Escola Família Agrícola de Santa Cruz do Sul - EFASC no âmbito de um processo formativo baseado na pedagogia da alternância. Os argumentos desenvolvidos têm por base pesquisa quanti-qualitativa realizada junto a estudantes e educadores entre 2014 e 2015. Os resultados indicam que o PPJ é o principal meio para discutir, refletir e organizar possibilidades concretas de inserção sócio-profissional dos estudantes, contribuindo significativamente para fortalecer o vínculo identitario do jovem com o meio onde vive e ampliando a percepção das oportunidades de diversificação e geração de renda. No entanto, identifica-se a necessidade de fortalecer ações pós-formação de modo a ampliar a contribuição da EFASC para o desenvolvimento regional.

Palavras-chave: agricultura familiar, educação do campo, juventude rural, pedagogia da alternância.

\section{THE PROFESSIONAL PROJECT OF YOUTH IN THE CONTEXT OF FAMILY FARMING SCHOOL OF SANTA CRUZ DO SUL}

\begin{abstract}
This article describes and analyzes the process of elaboration and development of the Young Professional Project - PPJ at Family Farming School of Santa Cruz do Sul - EFASC as part of a training process based on the pedagogy of alternation. The arguments put forward are based on quantitative and qualitative research conducted with students and teachers between 2014 and 2015. The results indicate that the PPJ is the main tool to discuss, reflect and organize concrete possibilities of socioprofessional integration of students, contributing significantly to strengthen the peasant identity among youth, promoting the attachment to the environment where they live, besides expanding the perception of opportunities for farming diversification and income generation. However, we identify the need to strengthen post-training actions in order to increase the contribution of EFASC for regional development.
\end{abstract}

\footnotetext{
${ }^{1}$ Tecnólogo em Horticultura (UERGS). Mestrado em Desenvolvimento Rural (PGDR/UFRGS). Professor da Escola Família Agrícola de Santa Cruz do Sul (EFASC). E-mail: adair.efasc@gmail.com

${ }^{2}$ Graduada em Agronomia (UFRGS). Mestrado em Fitotecnia (UFRGS). Doutorado em Desenvolvimento Rural (PGDR/UFRGS). Professora adjunta da Universidade Federal do Rio Grande do Sul (UFRGS). E-mail: flavia.marques@ufrgs.br
} 
Keywords: family farming; rural education; rural youth; pedagogy of alternation.

\section{INTRODUÇÃO}

As premissas desenvolvimentistas que sustentaram o processo modernizante nos espaços rurais, também deram vazão, durante muito tempo, à noção de que a educação deveria ser um instrumento para a superação de uma condição de 'atraso'. É assim que integrar a população rural ao 'mundo modernizado' constituiu a base para diretrizes educacionais que faziam parte de um conjunto de políticas voltadas para o crédito subsidiado, a pesquisa agropecuária e a extensão rural, em um claro movimento direcionado à modernização da agricultura. É neste contexto que a Educação Rural, seja formal ou informal, foi sendo pensada para atender interesses econômicos e políticos dominantes. Segundo Ribeiro (2010) ela foi estabelecida de forma contraditória, na medida em que, nas décadas de 1930-40, estimulava a permanência dos agricultores no campo e, adentrando nas décadas de 1950-60, passou a incentivar a saída da população do campo em direção às cidades, onde estariam as oportunidades de emprego.

Todavia, tal perspectiva logo recebeu críticas $^{3}$, que incidiram, basicamente, sobre quatro aspectos. O primeiro é o que trata da formação escolar voltada para o trabalho agrícola, tendo sido estabelecida como política compensatória e marginal. Outro aspecto criticado é o fato de que a educação rural foi elaborada e implantada para as populações do campo sem abrir espaço de diálogo com os sujeitos que lá viviam. O terceiro se refere à concepção de um rural do atraso oposto a um urbano do progresso. Esta perspectiva justificava a manutenção da base curricular centrada em um padrão 'urbanizador'. Por fim, o quarto aspecto apontado pelas críticas é que a proposta tratava de capacitar apenas uma parcela da população rural, de modo a favorecer a assimilação e difusão dos pacotes tecnológicos (agrotóxicos, máquinas, equipamentos, fertilizantes, cultivares melhoradas, etc.). De maneira geral, foram negligenciadas especificidades regionais, sociais, culturais e históricas, resultando em processos de exclusão social e um estreitamento no que tange às possibilidades pedagógicas para os sujeitos do campo.

Com a redemocratização do país, já nos anos 1980, surgem novos caminhos para a educação e as críticas anteriores passam a dar maior consequência ao debate. Neste contexto, nasce o "Movimento por uma Educação do Campo", com grande influência da Educação Popular e dos movimentos sociais que lutavam pela reforma agrária e pelo reconhecimento da agricultura familiar. Neste bojo, a melhoria das condições de vida das populações do campo é reivindicada juntamente com uma educação pensada desde a participação dos seus sujeitos, vinculada à sua cultura, aos seus locais e às necessidades humanas e sociais (CALDART, 2009). Costa et al. (2012) também ressaltam que a luta pela efetivação de uma educação pública de qualidade que viesse atender as particularidades do campo, emerge dos movimentos sociais e dos educadores, que propunham processos ensino-aprendizagem que articulassem saberes locais com o contexto curricular. Os autores, ainda, afirmam que é a partir da sanção das Diretrizes e Bases da Educação Nacional (LDB - Lei no 9.394, de 20 de dezembro de 1996) que se abre a possibilidade de estabelecer a educação do campo de forma diferenciada da educação urbana (COSTA et al., 2012, p. 57).

\footnotetext{
${ }^{3}$ Ver Paulo Freire $(1983 ; 1987 ; 2011)$.
} 
Dentre as possibilidades abertas, neste novo contexto institucional, passam a ser colocadas em prática uma série de diretrizes que vinham sendo apontadas pelo Movimento. Dentre elas, as Escolas Família Agrícola - EFAs, surgidas como uma proposta educacional para o campo, visando uma formação integral para a juventude, centrada na partilha e na interação entre todos os sujeitos envolvidos no processo de ensino e aprendizagem. Especificamente, as EFAs vão buscar inspiração e base teórico-metodológica na Pedagogia da Alternância para desenvolver um projeto político-pedagógico que respeite especificidades e a integralidade dos processos educacionais.

A Pedagogia da Alternância se constitui a partir de alguns princípios fundamentais: a responsabilidade e independência dos pais; a alternância como ligação entre teoria e prática; o respeito ao ritmo agrícola de cada região; a formação integral do jovem (NOSELLA, 2014). No entanto, ressalta-se que manter os princípios está longe de significar a propagação vertical ou padronizada de uma conduta pedagógica, considerando que a própria experiência nos mais diversos locais e contextos pode ser fonte de aprendizado e aprimoramento de instrumentos que qualifiquem a formação de jovens imersos nas heterogeneidades dos rurais contemporâneos. Neste sentido, o presente artigo pretende contribuir trazendo à reflexão alguns aspectos a partir da experiência da Escola Família Agrícola de Santa Cruz do Sul - EFASC, localizada no Vale do Rio Pardo no estado do Rio Grande do Sul - RS. Em especial, o objetivo é descrever e analisar a constituição do Projeto Profissional do Jovem - PPJ como um instrumento pedagógico inovador, cujo aprimoramento pode ser potencialmente importante para avanços na Educação do Campo.

A pesquisa ${ }^{4}$ que fornece subsídios para este artigo foi desenvolvida com base em revisão bibliográfica e análise documental, contando com a colaboração da Secretaria da EFASC para acesso a documentos como: plano de formação, plano de curso, plano pedagógico, regimento escolar e os PPJs elaborados e defendidos pelos estudantes. Uma segunda fase da investigação consistiu em levantamento realizado por meio da aplicação de um questionário online (Google Docs), contendo questões abertas e fechadas orientadas pelos eixos: (1) marco situacional dos jovens egressos (dados geográficos e trajetória pós-formação); (2) dados relacionados ao PPJ desenvolvido pelo estudante; e (3) dados sobre a sua inserção sócio-profissional. O questionário foi aplicado e respondido ${ }^{5}$ pelo universo de alunos egressos, que compreende duas turmas formadas, a primeira no ano de 2011, envolvendo 41 jovens e a segunda no ano de 2012 envolvendo 25 jovens, perfazendo um total de 66 egressos, oriundos de dez municípios do Vale do Rio Pardo. Complementarmente, entrevistas abertas em profundidade foram realizadas com três jovens egressos, também, onze monitores da Escola foram consultados e/ou entrevistados em diferentes momentos ao longo da pesquisa. Registra-se que a pesquisa foi facilitada pelo fato do primeiro autor atuar como monitor/professor na Escola.

A próxima seção do artigo traz a descrição do início das atividades da EFASC e esclarece aspectos sobre sua estrutura organizacional. Em seguida, são resgatados alguns elementos que permitem esclarecer a metodologia da Pedagogia da Alternância, considerando sua relevância como base para as dinâmicas de

\footnotetext{
${ }^{4}$ A pesquisa fez parte da Dissertação de Mestrado do primeiro autor, defendida junto ao Programa de PósGraduação em Desenvolvimento Rural da Universidade Federal do Rio Grande do Sul - PGDR/UFRGS. Neste artigo, os resultados da pesquisa são apresentados parcialmente.

${ }^{5} \mathrm{O}$ questionário foi acompanhado de um Termo de Consentimento Livre e Esclarecido para que os informantes pudessem expressar sua concordância quanto ao uso das informações coletadas.
} 
ensino e aprendizagem relacionadas à proposta do PPJ. Uma quarta seção está dedicada ao desenvolvimento do PPJ e a forma como dialoga com o contexto sóciofamiliar e regional. Finalmente, são tecidas considerações no intuito de fornecer uma apreciação qualitativa do PPJ e suas implicações.

\section{A CHEGADA DA ESCOLA FAMÍLIA AGRÍCOLA EM SOLO GAÚCHO}

Em 1969, ocorre a implantação da primeira EFA no estado do Espírito Santo mediante o apoio do Movimento de Educação Promocional do Espírito Santo MEPES (ZAMBERLAN, 2003), no entanto, seus fundamentos vinham das iniciativas de Educação Popular, desenvolvidas por Paulo Freire ainda no início da década de 1960. Em seguida, são fundadas mais algumas escolas, porém, as primeiras EFAs desenvolveram seu aprendizado fora dos currículos oficiais, enfrentando, inclusive, dificuldades para garantir a sua implantação, estrutura e funcionamento. Todavia, torná-las escolas de ensino regular passou a ser uma reivindicação por parte dos agricultores. Assim, em 1972, iniciam-se os cursos supletivos regulares ${ }^{6}$ e, em 1976 , amplia-se a oferta de ensino médio e técnico profissionalizante em agropecuária. Segundo Begnami (2003), nessa época muitas comunidades rurais passaram a ver nas EFAs uma possibilidade de acesso a uma educação contextualizada e que dialogava com as necessidades das famílias nos espaços rurais. É, a partir do final da década de 1980, que começa a expansão das EFAs pelo Brasil, tendo sido constituídas algumas Associações Regionais ${ }^{7}$, que tinham como missão animar, coordenar e assessorar, tanto as associações locais, como contribuir no processo de formação de monitores. Atualmente, as EFAs estão presentes em dezessete estados, com quase 150 escolas em funcionamento.

Em março de 2009, a primeira EFA é fundada no sul do Brasil, a EFASC, que, desde então, vem estabelecendo uma dinâmica de trabalho orientada pelos quatros pilares dos Centros Familiares de Formação por Alternância - CEFFAs. A ideia dos quatro pilares sintetiza as características invariáveis do movimento CEFFAs no mundo, buscando construir a unidade na diversidade são eles: (1) formação integral, envolvendo os aspectos técnico, profissional, intelectual, social, humano, ético e espiritual; (2) desenvolvimento do meio, caracterizado pela indissociabilidade com finalidade anterior e por possibilitar que jovens e adultos em formação convertam-se em atores de seu próprio desenvolvimento e do desenvolvimento do território onde estão inseridos; (3) metodologia da Pedagogia da Alternância, apresentada como adequada para o cumprimento das finalidades estabelecidas pelos pilares anteriores; (4) associação local, constituída principalmente pelas famílias, mas também pela ação de outras pessoas que aderem aos princípios propostos e que são os gestores do projeto educativo (GARCÍA-MARIRRODRIGA; PUIG-CALVÓ, 2010). A formação também pretende contribuir para que os jovens sejam capazes de exercer liderança e induzir processos de desenvolvimento local, estimulando-os para empreender atividades que possibilitem a diversificação das propriedades, bem como a geração de renda para a permanência no campo com qualidade de vida (COSTA, 2012; VERGUTZ, 2013).

Considerando a complexidade de colocar em prática todos estes propósitos, o processo de implantação da EFASC teve sua gênese em 2008, a partir da fundação da Associação Gaúcha Pró-Escolas Famílias Agrícolas - AGEFA,

\footnotetext{
${ }_{7}^{6}$ Atualmente esta modalidade chama-se Educação de Jovens e Adultos - EJA.

${ }^{7}$ Hoje, são onze Associações Regionais que, no plano nacional, compõem a União Nacional das Escolas Famílias Agrícolas do Brasil - UNEFAB, fundada em 1982.
} 
compreendendo uma forte mobilização regional, e desencadeando diversos encontros, seminários e intercâmbios com as EFAs de outros estados, além de reuniões com as instituições locais e com as comunidades rurais, que acabaram por dar legitimidade à implantação da escola. Contribuiu para isto o fato de que a região contava com poucas opções de ensino técnico agrícola e havia a preocupação com o êxodo rural, em especial da juventude.

A EFASC está inserida no Vale do Rio Pardo que, segundo Gomes (2014), se caracteriza pela presença maciça da agricultura familiar e pela baixa taxa de urbanização se comparada ao estado do Rio Grande do Sul, significando que o espaço rural é local de residência para muitas pessoas, mesmo quando trabalham nas sedes municipais. Além disto, é de se destacar uma problemática regional específica que está relacionada ao processo de integração de muitas famílias à indústria do tabaco, isto acaba por determinar, em grande medida, uma base homogeneizada da economia local (ETGES, 2001). Deste modo, o fortalecimento da agricultura familiar na região foi incorporando o imperativo da busca de alternativas produtivas que estimulassem a diversificação da produção e da economia local. Considerando dificuldades e/ou barreiras nos processos de substituição do tabaco, Rudnicki e Guerin (2014) assinalam que as famílias de agricultores, no Vale do Rio Pardo, identificam a educação como um fator relevante no que se refere à facilitação de mudanças econômico-produtivas na região.

\begin{abstract}
Nesse contexto, a EFASC se apresenta como uma escola que possibilita uma formação técnica em agricultura para os filhos de agricultores, demanda esta apresentada pela própria comunidade regional. Nesse caso, a responsabilidade da EFASC está em apresentar uma formação que vise debater e construir, junto aos jovens e suas famílias, possibilidades concretas de diversificação da produção, com a possibilidade de geração de novas fontes de renda aos agricultores e que garanta a produção de alimentos para a subsistência dos mesmos (COSTA, 2012, p. 122).
\end{abstract}

Costa (2012) apresentou uma minuciosa descrição e análise de todo processo histórico que culminou com a implantação da EFASC. Em sua análise, apresenta três movimentos chave deste processo: a) o envolvimento de um grupo de profissionais identificados com a educação do campo, com as causas sociais e necessidades da região; b) o apoio do Sistema de Crédito Cooperativo - Sicredi, que garantiu o financiamento para o processo de implantação e manutenção inicial da escola, além de promover discussão da proposta com seus associados, envolvendo-os no processo e promovendo a articulação institucional pela agregação do poder público local, cooperativas, associações, sindicatos e demais entidades representativas da agricultura familiar na região; c) o desenvolvimento de um intenso intercâmbio do grupo de monitores com as EFAs do Espírito Santo, de Minas Gerais e da Bahia, contando com a colaboração do professor Sergio Zamberlan na formação da equipe de monitores.

Fica evidente que há um processo dinâmico e ativo de construção da EFASC, seja pelo processo interno de discussão e qualificação, seja pela contínua ampliação de sua inserção regional, identificada pela participação de seus membros em distintos fóruns. O processo de reconhecimento e participação da Escola tem favorecido o diálogo com múltiplos atores locais, representados, por exemplo, nos mais de 30 parceiros públicos e privados que viabilizam sua manutenção junto com todas as famílias envolvidas. 
Em 2012, foi fundada a Associação Escola Família Agrícola de Santa Cruz do Sul - ASSEFASC, que está ligada à AGEFA e, assim, também à UNEFAB, estabelecendo uma ampliada articulação político-institucional com as demais EFAs. Atualmente, além da EFASC, existem outras duas escolas filiadas à AGEFA em funcionamento no RS: a Escola Família Agrícola da Serra Gaúcha - EFASERRA, implantada em 2013, situada na comunidade Terceira Légua em Caxias do Sul e a Escola Família Agrícola de Vale do Sol - EFASOL, localizada na Comunidade de Formosa, que iniciou suas atividades no ano de 2014. Ambas ofertam o Ensino Médio e Técnico Agrícola. Desde o início de 2015, está estabelecida no município de Canguçu, a Associação da Escola Família Agrícola da Região Sul - AEFASUL, cujo objetivo é ampliar a articulação junto ao Fórum da Agricultura Familiar da Região Sul para viabilizar a implantação de uma nova EFA.

Ressalta-se que a estrutura organizacional não está desvinculada dos processos pedagógicos em si e, neste sentido, um dos maiores esforços, conforme a pesquisa demonstrou, consiste em manter a horizontalidade nas relações, a participação e o comprometimento dos sujeitos da formação. Além disso, é do estabelecimento de uma ampla rede de parceiros públicos e privados que são garantidas as condições para a manutenção financeira, para o fortalecimento institucional ou para a atuação em demandas comuns sem, contudo, ferir a autonomia e os princípios políticos pedagógicos inerentes às EFAs.

\section{A PEDAGOGIA DA ALTERNÂNCIA E O PROJETO PROFISSIONAL DO JOVEM - PPJ}

A Pedagogia da Alternância, como já mencionado, é um dos pilares meio dos CEFFAs, tendo em sua essência a busca por processos educacionais contextualizados e fundamentados em ações que sejam pensadas pelos sujeitos, estabelecendo mecanismos que permitam vivenciar diferentes relações que os constituem e constituem o próprio campo.

A formação através da metodologia da Pedagogia da Alternância está organizada de modo a possibilitar ao estudante alternar, em um movimento cíclico, um tempo e espaço escolar, e outro tempo e espaço familiar ou sócio-profissional. Isto ocorre através do desenvolvimento de um método próprio, organizado em instrumentos pedagógicos que garantem a troca da experiência da vida cotidiana com a teoria e os saberes planejados e exigidos pela LDB. Esta organização singular oportuniza ao estudante tempo e espaço para a vivência e a convivência no ambiente escolar e no ambiente familiar e comunitário. Dessa maneira, afirma Vergutz (2013), esta metodologia

[...] oportuniza trocas, buscas, inquietações, perturbações, soluções, interações, diferenciações e associações com os saberes da família e da comunidade e os saberes da escola, possibilita que haja tempo e espaço para experimentar de maneira mais observadora-pesquisadora o contexto sócioprofissional-familiar e o contexto escolar, bem como apontar propostas de temáticas e alternativas a serem trabalhadas na ação educativa (VERGUTZ, 2013, p. 74).

O movimento alternado em dois espaços (família/comunidade e EFA) e o ritmo de três tempos distintos e interligados (Figura 1) se organiza, na EFASC, em sessões com duração de uma semana cada uma. Ou seja, a sessão começa na família/comunidade, passa pela escola e depois retorna à origem, onde resulta em 
pesquisas e experimentos. A expectativa fundamental é que tal movimento cíclico gere potencial para mudanças futuras, uma vez que possibilita trocas emergentes entre situações vivenciadas e o conhecimento apreendido na escola. Fundamentalmente, trata-se de compreender o processo educacional como um espaço de perguntas e não de respostas, um espaço de constante problematização, de investigação, de percepção e de criação e recriação de si e do mundo (VERGUTZ, 2013). Em outras palavras, "o mundo pronunciado, por sua vez, se volta problematizado aos sujeitos pronunciantes, a exigir deles novo pronunciar" (FREIRE, 1987, p. 78).

Figura 1 - Processo de Ensino e Aprendizagem na Pedagogia da Alternância.

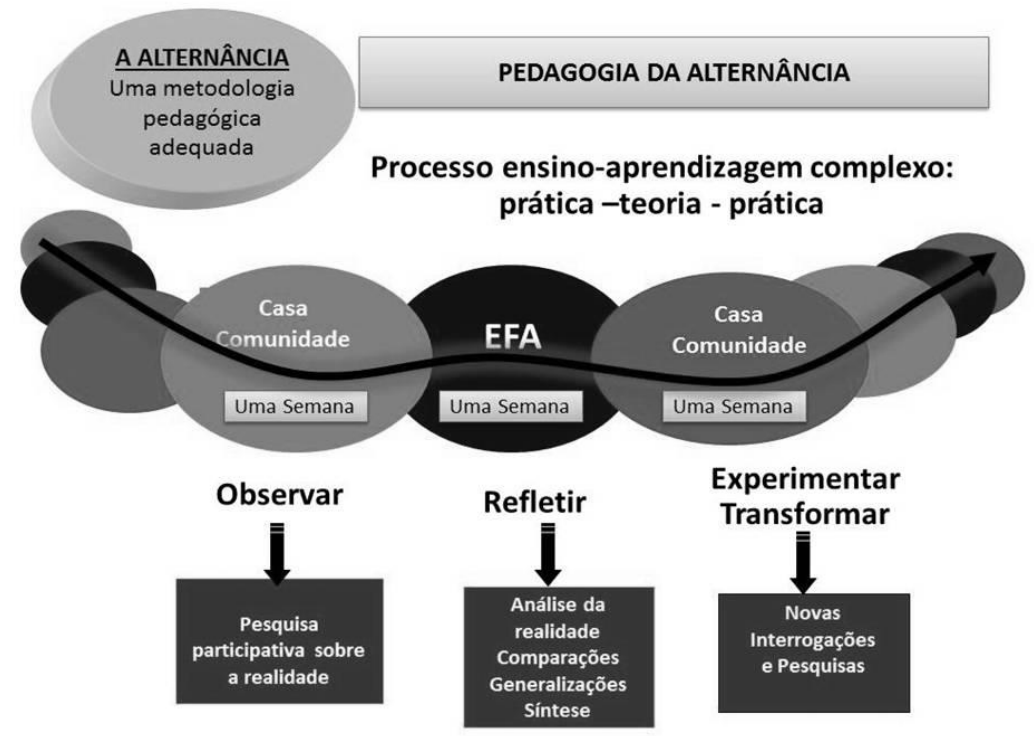

Fonte: adaptado de Puig-Calvó (2005, p. 29).

Essa prática educativa exige uma organização pedagógica que garanta a ação - reflexão - ação e, de forma significativa, permita a associação dessa ação e reflexão. Essa associação acontece através da singularidade dos instrumentos pedagógicos, que juntos e organizados compõem o Plano de Formação - PF. Segundo Gimonet (2007), sem o uso de instrumentos apropriados, a alternância passa a ser uma bela ideia pedagógica, mas sem realidade efetiva. São vários os instrumentos pedagógicos que tecem uma 'teia' entre os diferentes espaços e tempo de formação, o Quadro 1 traz alguns dos que vêm sendo aplicados no Brasil.

A EFASC desenvolve a grande maioria destes instrumentos, que orientam e atribuem sinergia na confecção do Plano de Formação - PF, entre eles está o Projeto Profissional do Jovem - PPJ. Além desses, outros foram sendo construídos coletivamente pela equipe de educadores da EFASC com vistas a melhorar o processo pedagógico, tais como o estágio de vivência, seminário de aplicação e 
momento do envio ${ }^{8}$. O interessante é destacar que as EFAs mantêm autonomia para usar, criar e adequar o uso dos instrumentos pedagógicos conforme o seu contexto, estabelecendo coerência com os princípios anteriormente mencionados.

Quadro 1 - Descrição dos instrumentos pedagógicos aplicados nos CEFFAs do Brasil.

\begin{tabular}{|c|c|}
\hline Instrumento pedagógico & O que é? \\
\hline Plano de Estudos & Pesquisa participativa que o jovem aplica em seu meio. \\
\hline Colocação em Comum & $\begin{array}{l}\text { Socialização e sistematização da pesquisa do Plano de } \\
\text { Estudos. }\end{array}$ \\
\hline Caderno da Realidade & $\begin{array}{l}\text { Livro da vida do(a) jovem onde se registra as suas } \\
\text { pesquisas e todas as atividades ligadas ao Plano de Estudo } \\
\text { nos ciclos das alternâncias. }\end{array}$ \\
\hline Viagens e Visitas de Estudos & $\begin{array}{l}\text { Uma atividade complementar ao tema do Plano de Estudos. } \\
\text { Implica em intercambiar experiências concretas. }\end{array}$ \\
\hline Colaborações Externas & $\begin{array}{l}\text { São palestras, testemunhos ou cursos complementares ao } \\
\text { tema pesquisado pelo PE, contando com a colaboração de } \\
\text { profissionais, lideranças ou outros parceiros. }\end{array}$ \\
\hline Cadernos Didáticos & $\begin{array}{l}\text { É uma modalidade de "livro didático" elaborado para dar o } \\
\text { aprofundamento ao tema do Plano de Estudos. }\end{array}$ \\
\hline Estágios & $\begin{array}{l}\text { Vivências práticas em meios produtivos, organizações } \\
\text { sociais, serviços, empresas em geral. }\end{array}$ \\
\hline Atividades de Retorno & $\begin{array}{l}\text { Experiências e atividades concretas na família ou } \\
\text { comunidade a partir dos Planos de Estudos. }\end{array}$ \\
\hline $\begin{array}{l}\text { Visitas às famílias e } \\
\text { Comunidades }\end{array}$ & $\begin{array}{l}\text { Atividade realizada pelos monitores para conhecer a } \\
\text { realidade e acompanhar as famílias e jovens em suas } \\
\text { atividades produtivas e sociais. Representa a extensão da } \\
\text { CEFFA em seu meio. }\end{array}$ \\
\hline Tutoria & $\begin{array}{l}\text { Acompanhamento personalizado para motivar os estudos, } \\
\text { incentivar as pesquisas, o engajamento social, a integração } \\
\text { e vida de grupo, o projeto de vida profissional. }\end{array}$ \\
\hline Serões de Estudo & $\begin{array}{l}\text { Espaço para debates sobre temas variados e } \\
\text { complementares escolhidos junto com os jovens. }\end{array}$ \\
\hline $\begin{array}{l}\text { Caderno de } \\
\text { Acompanhamento da } \\
\text { Alternância }\end{array}$ & $\begin{array}{l}\text { Um documento que registra o que é feito na escola e no } \\
\text { meio sócio-profissional. É um instrumento de comunicação } \\
\text { entre a escola-família e família-escola. }\end{array}$ \\
\hline Projeto Profissional & $\begin{array}{l}\text { O jovem vai amadurecendo ao longo dos anos o que } \\
\text { aprende e desenvolve no campo da produção, da } \\
\text { transformação ou de serviço, bem como continuação dos } \\
\text { estudos. No último ano, o projeto e sistematizado a partir de } \\
\text { um roteiro definido pelo CEFFA e da orientação dada pela } \\
\text { equipe de monitores. }\end{array}$ \\
\hline Avaliação & $\begin{array}{l}\text { As avaliações são contínuas e abrangem aspectos do } \\
\text { conhecimento, das habilidades, convivência em grupo, } \\
\text { posturas. Todos avaliam e são avaliados. }\end{array}$ \\
\hline
\end{tabular}

Fonte: De Burghgrave (2011, p. 149-150).

\footnotetext{
${ }^{8} \mathrm{O}$ estágio de vivência é um intercâmbio entre as famílias, onde cada jovem passa uma semana residindo junto à família de seu colega (previamente escolhido), convivendo e conhecendo o contexto social, econômico e produtivo local. O seminário de aplicação é um dispositivo pedagógico criado pela EFASC para verificar o andamento das práticas, estudos e pesquisas dos estudantes. Já, o momento do envio acontece todas as sextas-feiras, sendo o ato de preparação e motivação para o início de uma nova sessão familiar (no meio sócio-profissional).
} 
$\mathrm{Na}$ ação pedagógica da EFA, alternância e projeto andam juntos, estas definições são mobilizadas de modo interdependente. O projeto de escolarização é desenvolvido durante o processo formativo, possibilitando o estudo reflexivo da realidade e constituindo base de dados, informações, experiências e reflexões. É justamente este processo que culmina na elaboração do projeto de inserção profissional ao final do processo de formação.

No Brasil, não há muitos precedentes quando o assunto é o roteiro adotado pelas EFAs para a elaboração de projetos profissionais, tampouco, existem muitas informações bibliográficas sobre tal metodologia. Por outro lado, a ideia central não é estabelecer um padrão a ser seguido, ao contrário, é contribuir com reflexões que possam, a partir da experiência acumulada, qualificar os percursos formativos dos jovens.

Ao longo da sua formação, todos os estudantes da EFASC elaboram o PPJ, sendo a principal ferramenta para articular o saber popular e o conhecimento científico, uma vez que é elaborado e embasado a partir da realidade da família, da propriedade (Unidade de Produção Familiar - UPF), da comunidade e da região, sendo considerado o "fio condutor da formação em alternância" (GARCíAMARIRRODRIGA; PUIG-CALVÓ, 2010, p. 174). Ele está articulado e presente nas várias etapas do plano de formação, culminando com a sua apresentação, defesa e experimentação ao final do processo formativo. No âmbito dos CEFFAs, entre outras definições, o PPJ é

[...] também chamado de "projeto de inserção profissional", "projeto de vida", "projeto pessoal". É o resultado de uma análise minuciosa da situação histórico-familiar, da infraestrutura para a produção agropecuária, do planejamento produtivo, das condições ambientais e climáticas, das políticas públicas, da realidade do comércio e do mercado consumidor, dos aspectos artístico-culturais, entre outros, que caracterizam a realidade do estudante, no âmbito familiar, do seu município e de sua região que, aliados aos conhecimentos proporcionados pela proposta metodológica do CEFFA, à aptidão do jovem, à motivação e planejamento, constituem sua proposta de inserção profissional (SANTOS; PINHEIRO, 2005 , p. 41).

O projeto profissional, segundo Puig-Calvó (2002), faz de processos de avaliação e exigências para conclusão dos cursos, mas deve, sobretudo, dar sentido à formação e à vida dos estudantes, estimulando que encontrem suas próprias soluções com criatividade. Vai ficando claro que a proposta da introdução do PPJ como estratégia pedagógica é interligar tecnicamente as aprendizagens desenvolvidas no ambiente escolar com o ambiente sócio-profissional e/ou familiar. Para o desenvolvimento da proposta, há, ainda, o envolvimento permanente de monitores e tutores ${ }^{9}$, que buscam interagir com os estudantes, contribuindo, por um lado, com os processos de aprendizagem e, por outro, com a articulação com as comunidades e/ou famílias, de modo a auxiliar na qualificação e adequação dos projetos às distintas realidades diagnosticadas.

O Plano de Formação organiza, estrutura e dá sentido a todo o percurso formativo do jovem alternante na EFA, tanto durante o tempo de formação no meio sócio-profissional familiar, como durante a formação escolar propriamente dita,

\footnotetext{
${ }^{9}$ A tutoria prevê acompanhamento personalizado do educando por um Monitor, o trabalho é desenvolvido individualmente, porém, dentro de um processo dialógico, estabelecendo uma relação de confiança.
} 
representando, segundo Gimonet (2007, p. 70), "a orquestração do conjunto de componentes do dispositivo pedagógico". Na EFASC, o PF é construído coletivamente e reavaliado anualmente, buscando expressar e envolver de forma sistematizada e orgânica as necessidades e demandas dos jovens alternantes, de suas famílias e das comunidades.

Deste modo, é a partir da organização do Plano de Formação que os demais instrumentos da Pedagogia da Alternância são organizados, inclusive, o PPJ. O PF da EFASC está organizado a partir de três grandes temas geradores e seus respectivos objetivos gerais, que estabelecem diretrizes para os demais desdobramentos e instrumentos pedagógicos, estabelecidos de forma distinta para cada ano letivo. Para o primeiro ano o tema é "Eu, a família e a terra", tendo como objetivo geral: conhecer o contexto sócio-ambiental-familiar e reconhecer-se neste meio tornando-se, assim, agente de transformação. $O$ tema do segundo ano compreende "Tecnologias, técnica e desenvolvimento", o objetivo relacionado é conhecer, resgatar, criar e implementar tecnologias e alternativas sociais e produtivas para o desenvolvimento. Para o terceiro ano o tema gerador envolve "Projeto(s) e desenvolvimento humano", com o objetivo de elaborar e implementar o PPJ, buscando o desenvolvimento local, qualidade de vida, sustentabilidade e renda.

A elaboração do PPJ é concluída no terceiro ano, no entanto, deve-se destacar que ele é desenvolvido ao longo de todo Ensino Médio, contemplando três ciclos interpenetrados e interdependentes (Figura 2) que foram pensados para auxiliar a contextualização dos projetos às realidades vividas pelos estudantes.

Figura 2 - Ciclos do PPJ e sua relação com o Plano de Formação.

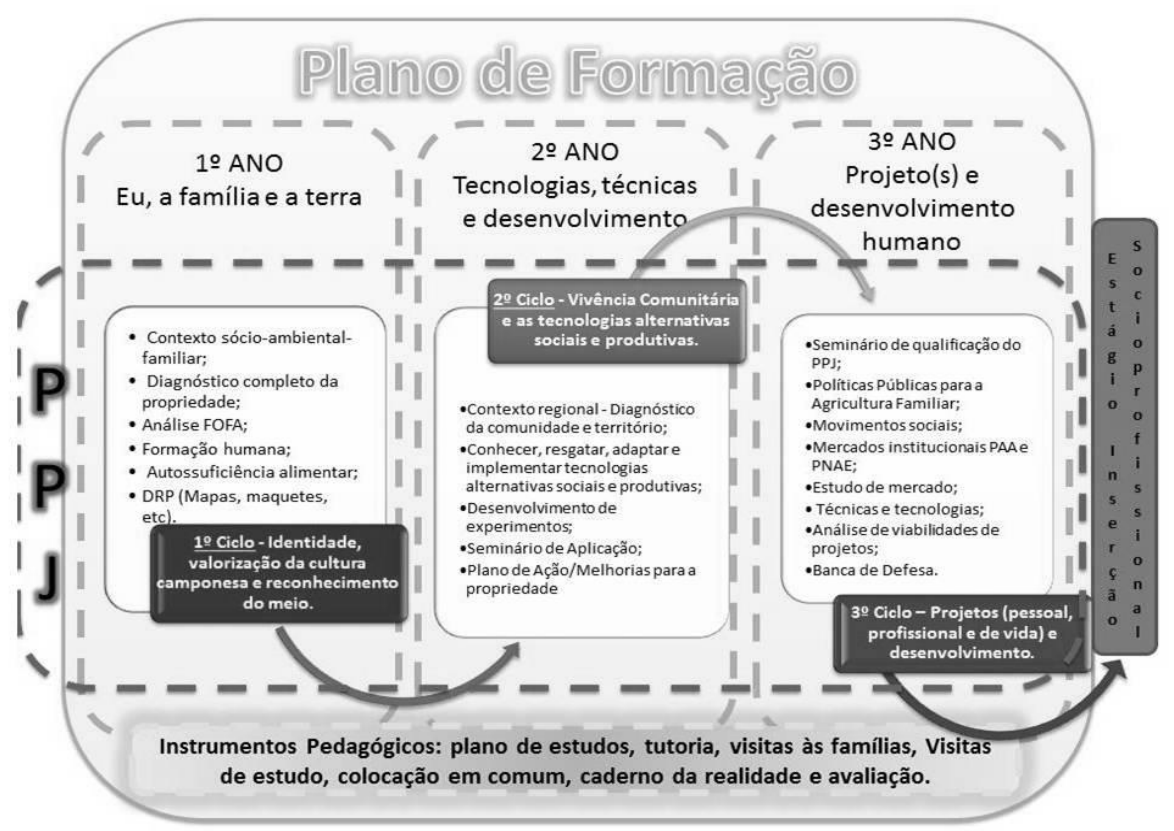

Fonte: elaborado pelos autores. 
Entrando no segundo ciclo, os estudantes são provocados a refletir sobre as mudanças que ocorreram no campo em função da modernização agrícola e as tecnologias apropriadas especialmente tomando um enfoque agroecológico. Para além das técnicas, o jovem é instigado a pensar sobre relações de poder, o sistema integrado de produção, os pacotes tecnológicos e as contradições do desenvolvimento. O trecho de entrevista com Monitor Samuel Felipe Kappaun transcrito abaixo é revelador neste sentido.

\begin{abstract}
[...] o jovem vai percebendo, a partir de seus estudos e práticas, que existem, sim, possibilidades produtivas no meio onde vive; que the podem dar qualidade de vida e que também geram uma boa renda. Após conseguir fazer essas reflexões durante a alternância e compreendendo toda a política socioambiental e econômica que existe por trás disso tudo, nossos estudantes começam a quebrar diversos paradigmas sobre a produção agrícola da região, dentre eles, podemos citar a possibilidade de se produzir sem uso de agrotóxicos e o calcanhar de Aquiles da região do Vale do Rio Pardo, a produção de tabaco, onde a maioria dos discursos feitos, tanto por autoridades públicas ou privadas como pelos próprios agricultores de que "não existe cultura agrícola que renda mais por área que o tabaco". Os estudantes da EFASC vêm comprovando justamente o contrário desse discurso, e mais, conseguem comprovar na prática e com dados estatísticos da produção e os coletados por eles próprios durante suas práticas agrícolas que na pequena propriedade rural pode-se ter culturas que tenham uma rentabilidade muito superior que 0 tabaco, sem falar na qualidade de vida, onde se pode produzir alimentos sem o uso de defensivos agrícolas, com custo de produção baixo e com apenas mão de obra da família (entrevista Monitor, janeiro, 2015).
\end{abstract}

A fala do Monitor ajuda a evidenciar a relação entre as vivências, a aquisição de conhecimentos e habilidades com a construção novas possibilidades e oportunidades no desenvolvimento dos projetos profissionais. Nesta etapa, o jovem além de dar continuidade à elaboração da análise da propriedade, desenvolve outro diagnóstico, este voltado à comunidade. Além disto, são convidados a construir um Planejamento Estratégico de curto, médio e longo prazo, culminando com a elaboração de um Plano de Ação/Melhorias para a propriedade, projetando as suas perspectivas profissionais para até cinco anos. Porém, é importante destacar que, por envolver decisões que envolvem o estudante e a família, este processo prioriza o diálogo, o debate e a socialização.

O terceiro ciclo é o momento de fechamento ou alinhamento das discussões desenvolvidas ao longo dos anos de formação. O principal foco deste último ciclo (terceiro ano da EFASC) está na elaboração do PPJ, envolvendo esforços de integrar e contextualizar o projeto na realidade da família, da propriedade, da comunidade e do território. Nesta fase, os vários instrumentos pedagógicos contribuem no processo de reflexão para a construção do projeto. Um exemplo é o desenvolvimento dos Planos de Estudo, que se destinam a explorar em maior detalhe uma temática identificada como relevante para o projeto. A Tutoria é bastante determinante na orientação e na problematização com relação à temática e aos objetivos do PPJ, sendo realizada de forma personalizada, primando pelo diálogo entre os pais, o jovem e monitores. 
As Visitas de Estudo favorecem o contato com novas experiências, em muitos casos, ocorrem nas propriedades de jovens egressos, que já implantaram os seus projetos de diversificação da unidade familiar. Além dos contatos tutorestudante-família e a possibilidade de visitar outras iniciativas em andamento, ainda existe o desenvolvimento de experimentos, nos quais são testadas práticas nas condições existentes no meio, buscando identificar aspectos podem contribuir para o êxito do projeto. Thies e Mello (2012), ao estudar o envolvimento de estudantes em processos de experimentação, concluem que o maior contato com a realidade contribuiu para capacitá-los a interpretar e agir em situações complexas.

A articulação entre esses instrumentos pedagógicos tem sido fundamental para a formação integral. Aqui, destaca-se apenas alguns dos ciclos que se referem especificamente ao desenvolvimento do PPJ, cuja função é também introduzir perspectivas e possibilidades em relação à inserção sócio-profissional dos jovens para além da vida escolar. Neste sentido, a egressa Andressa Elisandra de Bastos corrobora afirmando que "[...] o PPJ realmente é um projeto que visa todo o meio em que o jovem vive, construindo assim um projeto de vida para o mesmo" (entrevista, junho de 2014).

Analisando-se a proposta do PPJ, e como ela se articula com os demais instrumentos ao longo da formação, é possível afirmar que os projetos não poderiam ser desenvolvidos fora do contexto da Pedagogia da Alternância. Os movimentos de 'idas e vindas' que a alternância favorece (e preconiza) são fundamentais para que o processo de formação expanda relações para dentro das famílias e para as comunidades, abrindo possibilidades para novas formas de aprendizagem com geração de conhecimento. Sem a rotina 'alternante' julga-se que ficaria muito difícil construir um 'projeto de vida' enraizado no contexto local, seja do ponto de vista técnico, econômico, ambiental, social ou cultural.

\section{O DESENVOLVIMENTO DOS PPJS PARA ALÉM DA EFASC}

Para o processo formativo promovido na EFASC, o PPJ é fundamental, como já mencionado, sua construção propicia interligar, de forma humano-ideológica e técnica, as aprendizagens desenvolvidas com o ambiente sócio-profissional e/ou familiar. Vergutz (2013) ainda reforça que o PPJ, de forma sistêmica, leva em conta a complexidade de todos os elementos e fatores que se relacionam com a vivência dos estudantes e de suas famílias, incentivando uma gestão partilhada, conectada e co-responsável do trabalho na agricultura. A percepção do jovem egresso Diego Henrique Limberger reforça esta afirmação, como exemplificado no trecho a seguir.

[...] o PPJ é um grande instrumento de formação técnica, de conhecimento de realidade, de envolvimento familiar e geração de renda, atentando ainda mais a possibilidade de viver bem no campo, com qualidade de vida e renda, tendo todas as possibilidades de estudar, se formar, e mexer na comunidade, contribuindo no desenvolvimento do meio. Todo o PPJ é uma construção, e que por cada um é melhorado todos os anos (entrevista, julho, 2014).

Assim, o PPJ é, sem dúvida, educativo, uma vez que é desenvolvido com o acompanhamento da escola, mobilizando e articulando os diferentes conhecimentos, no entanto, é também profissional, na medida em que propõe o exercício da resolução de problemas da vida produtiva, inter-relacionando educação e trabalho. O PPJ pode ser considerado um elemento provocador ao instigar o jovem e a família 
a pesquisar, buscar respostas, estudar e construir coletivamente alternativas para a UPF e para a comunidade. No que tange as relações com a comunidade propiciadas pela elaboração de um projeto profissional, Costa (2012) afirma que

[...] é possível os jovens pensarem o desenvolvimento do seu meio, pensando na região como um todo, a partir de suas práticas sustentáveis, de uma agropecuária que tem no meio ambiente um aliado para produzir mais e melhor (COSTA, 2012, p. 203).

Todavia, talvez o maior desafio da proposta resida justamente na pretensão de propor ações relacionadas ao desenvolvimento do meio, ou seja, educar e formar para agir sobre uma dada realidade concreta. Considerando, ainda, que tal intervenção sobre o meio também depende de articulações entre instituições e outros sujeitos. Como destacam García-Marirrodriga e Puig-Calvó (2010, p. 176) "cada estudante deve formular e pôr em prática quando seja possível, um projeto profissional ao terminar a sua formação". Neste sentido, há dados animadores levantados pela pesquisa que mostram que os jovens egressos da EFASC estão implantando os projetos produtivos e de geração de renda na medida do possível (Figura 3).

Figura 3 - Percentagem de PPJs implantados pelos egressos das turmas 2010 e 2011.

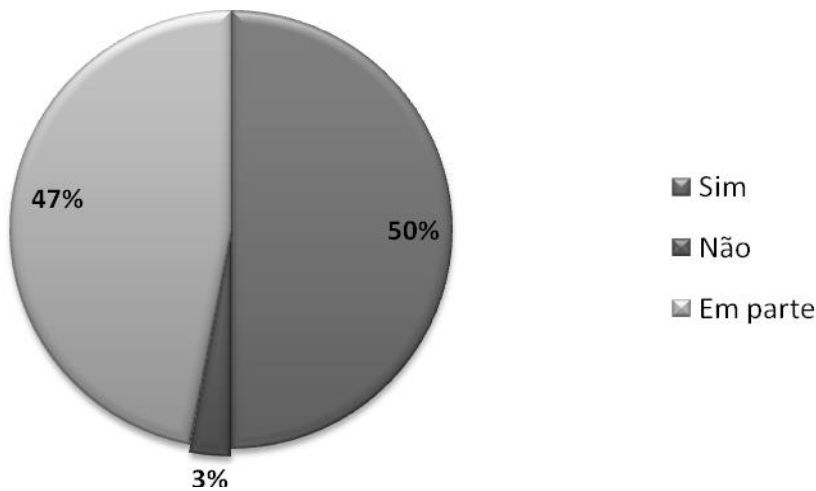

Fonte: elaborado pelos autores.

Conforme a figura acima, é possível verificar que metade dos jovens egressos conseguiu implantar o projeto na totalidade. Os relatos abaixo mencionam alguns aspectos relacionados à implantação parcial.

O projeto cumpre sua tarefa implementando a diversificação da propriedade, porém, um de seus objetivos que era a comercialização do aipim não está acontecendo, contudo, se pode dizer que foi aplicado em partes (Evandro de Oliveira Lucas, junho de 2014).

O Projeto esta sendo aplicado em partes, ocorreram algumas mudanças referente ao destino final do produto, eu e minha família incrementamos o trabalho, agora, além de fornecer alimentos à propriedade, comercializamos tomate orgânico na 
Cooperativa Ecovale e participamos junto ao Grupo formado no CAPA $^{10}$ (Bruna Betina Greiner, junho de 2014).

Entre os PPJs analisados, 38\% tinham foco na produção animal e $62 \%$ na produção vegetal, sendo uma parte deles com enfoque agroecológico. Para exemplificar a prática agroecológica no universo dos jovens egressos, se pode citar a experiência do casal Anderson Rodrigo Richert e Micaela Hister ${ }^{11}$, que se conheceram na Escola e, hoje, moram em Linha Santana, município de Venâncio Aires. Eles participam do Grupo Ecológico Eco da Vida, que existe há 15 anos na comunidade. Estes jovens implantaram o PPJ e estão produzindo, numa área de 0,7 hectares junto à propriedade dos pais, mais de 30 espécies de hortaliças com certificação participativa pela Rede ECOVIDA, participam de feira na cidade e, ainda, comercializam seus produtos em mercados institucionais.

Também, observa-se que havia projetos que previam a necessidade de recursos para a sua implantação, mas o acesso ao crédito foi pouco expressivo, somente acessaram financiamento via PRONAF $^{12}$ ou FEAPER $^{13}$ jovens que investiram valores superiores a cinco mil reais. Os dados da pesquisa apontaram que somente $11 \%$ dos projetos necessitaram de financiamento externo para serem implantados.

Porém, as opiniões expressas pelos egressos, ao longo da pesquisa, permitem refletir que, embora tenham surgido algumas políticas públicas específicas para os jovens rurais nos últimos anos, ainda tem sido difícil o acesso a financiamentos ou apoios de outra natureza para projetos inovadores. Os egressos entrevistados mencionam, por exemplo, a necessidade de existir um financiamento específico para a implantação dos PPJs, que pudesse cobrir os gastos com a implantação e manutenção do projeto, talvez na forma de um subsídio não reembolsável. Apoios desta natureza serviriam, então, como forma de incentivo ao desenvolvimento de novas atividades nas propriedades e à permanência da juventude no campo, conforme os relatos a seguir.

Ter à disposição do estudante uma renda para que possa implementar seu PPJ. Sem que ele precise devolver tal valor (Daiane Andresa Schubert, julho de 2014).

\begin{abstract}
Ter algum valor financeiro mensal para que o jovem possa aplicar seu projeto sem se envolver nas atividades que the tirem tempo ao executá-lo durante dois anos em média. Mesmo com o conhecimento técnico ter alguém que possa dar continuidade nos projetos dos jovens, ou seja, alguém pago para auxiliar os jovens para não haver um desgaste em sair muito da propriedade (Emerson Luis Rech, julho de 2014).
\end{abstract}

A avaliação geral é de que, com $97 \%$ dos PPJs implantados (64 jovens), o resultado pode ser considerado positivo no contexto da proposta da Escola, primeiro, porque pode estar indicando a pertinência dos temas em foco e, em segundo lugar, porque o instrumento pedagógico PPJ parece estar cumprindo seu lado mais 'ousado' que é fazer parte, de certa forma, dos projetos de vida dos jovens

\footnotetext{
${ }^{10}$ Centro de Apoio ao Pequeno Produtor.

${ }^{11}$ Ambos também estão cursando o Curso Superior de Tecnologia em Horticultura na Universidade Estadual do Rio Grande do Sul, em Santa Cruz do Sul.

12 Programa Nacional de Fortalecimento da Agricultura Familiar.

${ }^{13}$ Fundo Estadual de Apoio ao Desenvolvimento dos Pequenos Estabelecimentos Rurais.
} 
e suas famílias. No entanto, é necessário ter claro que a implantação de um PPJ, ainda que aporte em si o potencial de empreender, vai depender de uma série de condições objetivas que nem sempre estarão sob a ingerência direta do egresso, da família, da escola e mesmo da comunidade. Assim, se faz necessário, além de elaborar e exercitar o projeto profissional, estimular o acesso às políticas públicas e fortalecer o envolvimento da juventude na reivindicação por elas.

Considerando as relações 'para fora' do ambiente escolar e/ou do período de formação, a pesquisa evidencia a necessidade de haver um acompanhamento pós-formação na EFASC. As opiniões de egressos, transcritas abaixo, retratam a demanda por um acompanhamento na implantação e do desenvolvimento dos projetos.

No decorrer de nossa formação, temos o total acompanhamento desde os primeiros passos do PPJ, sua elaboração e aplicação, o que deveria ser implementado é uma espécie de acompanhamento pós-projeto (pós PPJ) que sem dúvida é fundamental para o jovem e comunidade (Régis Dattein Solano, junho de 2014).

Está tudo bem. A única coisa é os monitores devem, pelo menos, fazer uma visita aos egressos para ver o que eles estão fazendo em suas propriedades (Felipe Moraes Mello, junho de 2014).

Porém, existem limites para uma atuação 'pós-formativa', visto que se trata de uma escola comunitária, onde os recursos são escassos. Deste modo, a alternativa poderia estar na ampliação e fortalecimento de redes com organizações governamentais e não governamentais, de modo a estimular e desenvolver uma articulação política e técnica que viesse a contribuir para uma incidência mais generalizada de desenvolvimento do meio a partir de um trabalho continuado, partindo-se das propostas educacionais. Potencialmente, tais articulações poderiam estabelecer um elo entre as diferentes realidades e comunidades, fortalecendo relações de cooperação, solidariedade e ampliando a sustentabilidade dos projetos. Ainda, é de se registrar que existem algumas experiências nas EFAs do Brasil em que os egressos se uniram para criar uma cooperativa de 'técnicos' justamente para atuar na articulação, mobilização e Assistência Técnica e Extensão Rural - ATER. A pesquisa parece indicar que esta pode ser uma forma de dar conta desta demanda existente entre os egressos no território de atuação da EFASC.

\section{CONSIDERAÇÕES FINAIS}

Ao longo dos sete anos de existência, a EFASC tem ampliado sua inserção regional e angariado reconhecimento estadual e nacional, assim, uma primeira consideração é de que a Escola faz parte de avanços que vêm sendo construídos no Brasil no que tange à Educação do Campo, em consonância com processos similares em outros países. Os levantamentos da pesquisa permitem, também, apontar que a Pedagogia da Alternância tem se mostrado um caminho fundamental para a transformação das ações educativas no campo, isto não significa que seus desdobramentos e instrumentos não possam ser continuadamente qualificados.

Neste sentido, a análise do desenvolvimento do PPJ autoriza confirmar que ele está situado em uma matriz complexa, sistêmica e interdependente, que mobiliza e articula diferentes sujeitos, saberes e recursos. Sendo assim, este instrumento 
pedagógico mostra-se fundamental para alcançar os propósitos de uma formação integral que suscite a inquietação nos jovens envolvidos com a construção do seu projeto profissional que, muitas vezes, se confunde com próprio projeto de vida.

O desenvolvimento dos projetos, com êxito, mostra-se possível com o envolvimento e o engajamento das famílias, dos educadores e de uma série de parcerias locais (i.e., associações, cooperativas, movimentos sociais, órgãos governamentais). Esta articulação para a elaboração e implantação destes projetos, dentro do processo formativo pretendido, passa a interferir e impactar diretamente na vida da família agricultora, na comunidade e no território, por isto, o PPJ pode ser considerado um instrumento de ação e intervenção. Por outro lado, no que se refere à contribuição para o desenvolvimento do meio, a execução plena da potencialidade dos projetos coloca desafios importantes, considerando que geram demandas de investimentos e/ou políticas públicas específicas. Deste modo, é interessante que haja condições para o estabelecimento de redes de cooperação que venham estimular a inserção social e profissional dos jovens egressos de modo permanente e sem descontinuidades.

A maioria dos PPJs foi implantada e os planos seguem ativos, contando com um bom número de jovens inseridos nas atividades produtivas em suas propriedades. No entanto, os jovens apontam a necessidade de um acompanhamento pós-formação, promovendo uma articulação técnica e política que dê suporte aos projetos. Com base na análise realizada, é possível afirmar que essa articulação pós-formação pode ser essencial para a sustentabilidade institucional, indo um pouco além, pode-se vislumbrar que tal acompanhamento pode significar uma a ampliação da contribuição da EFASC para o desenvolvimento rural na região do Vale do Rio Pardo.

\section{REFERÊNCIAS}

BURGHGRAVE. T. Vagabundos, não senhor cidadãos brasileiros e planetários: uma experiência educativa pioneira do Campo. Orizona: UNEFAB, 2011.

CALDART, R. S. Por uma educação do campo: traços de uma identidade em construção. In: ARROYO, M., CALDART, R., MOLINA, M. C. Por uma educação do campo. Petrópolis: Vozes, 2009. p. 147-158.

COSTA, J. P. R. Escola Família Agrícola de Santa Cruz do Sul - EFASC: uma contribuição ao desenvolvimento da região do Vale do Rio Pardo a partir da pedagogia da alternância. Dissertação (Mestrado em Desenvolvimento Regional), Programa de Pós-Graduação em Desenvolvimento Regional, Universidade de Santa Cruz do Sul, Santa Cruz do Sul, 2012.

COSTA, J. P. R.; COSTA, N. M. V.; SILVA, M. R. P. Os desafios e as práticas pedagógicas do professor-pesquisador do campo no Nordeste paraense/Amazônia brasileira. Extensão Rural, v. 19, n. 2, p. 55-76, 2012.

ETGES, V. E. A região no contexto da globalização: o caso do Vale do Rio Pardo. In: VOGT, O.; SILVEIRA, R. Vale do Rio Pardo: (re)conhecendo a região. Santa Cruz do Sul: Edunisc, 2001.

FREIRE, P. Pedagogia da esperança: um reencontro com a pedagogia do oprimido. 17 ed. São Paulo: Paz e Terra, 2011. 
. Extensão ou comunicação? Trad. de Rosisca Darcy de Oliveira. 7 ed. Rio de Janeiro: Paz e Terra, 1983.

Pedagogia do oprimido, Rio de Janeiro: Paz e Terra, 1987.

GARCÍA-MARIRRODRIGA, R.; PUIG-CALVÓ, P. Formação em alternância e desenvolvimento educativo dos CEFFAs no mundo. Belo Horizonte: O lutador, 2010.

GIMONET, J. C. Praticar e compreender a pedagogia da alternância dos CEFFAS. Petrópolis: Vozes, 2007.

GOMES, A. C. A operacionalização do mercado institucional de alimentos no contexto do Vale Do Rio Pardo: o caso da Cooperativa Leoboqueirense de Agricultores Familiares. Dissertação (Mestrado em Desenvolvimento Regional), Programa de Pós-Graduação em Desenvolvimento Regional, Universidade de Santa Cruz do Sul, Santa Cruz do Sul, 2014.

PUIG-CALVÓ, P. Formação Pessoal e Desenvolvimento Local. In: Pedagogia da alternância: formação em alternância e desenvolvimento sustentável, Brasília: União Nacional das Escolas Famílias Agrícolas do Brasil, 2002. p. 126-146.

RIBEIRO, M. Movimento camponês, trabalho e educação - liberdade, autonomia, emancipação: princípios/fins da formação humana. São Paulo: Expressão Popular, 2010.

RUDNICKI, C.; GUERIN, Y. S. As mediações na trajetória de vida dos agricultores do tabaco no Rio Grande do Sul. Extensão Rural, v. 20, n. 1, p. 27-36, 2014.

SANTOS, I. F.; PINHEIRO, J. E. L. O CEFFA e o projeto profissional do jovem. Revista da Formação por Alternância, Brasília, v. 1, n. 1, 2005.

THIES, V. F.; MELLO, U. P. Procedimentos educativos de transição agroecológica: o caso da experimentação participativa na FUNDEP (RS). Extensão Rural, v. 19, n. 2, p. 109-124, 2012.

VERDEJO, M. E. Guia prático: DRP. Brasília: Gráfica ASCAR, 2006. p. 61.

VERGUTZ, C. L. B. Aprendizagens na pedagogia da alternância da Escola Família Agrícola de Santa Cruz do Sul. Dissertação (Mestrado em Educação), Programa de Pós-Graduação em Educação, Universidade de Santa Cruz do Sul, Santa Cruz do Sul, 2013.

ZAMBERLAN, S. Formação e desenvolvimento sustentável: o lugar da família na vida institucional da escola-família - Participação e Relações de Poder. Dissertação (Mestrado Internacional em Ciências da Educação), Universidade Nova de Lisboa - Portugal e Université François Rabelais de Tours - France, 2003. 